\title{
Benefit of convection permitting climate model simulations in the representation of convective precipitation
}

\author{
G. Fosser $\cdot$ S. Khodayar $\cdot$ P. Berg
}

Received: 12 February 2013 / Accepted: 2 July 2014 / Published online: 2 August 2014

(C) The Author(s) 2014. This article is published with open access at Springerlink.com

\begin{abstract}
A major source of uncertainty in regional climate model (RCM) simulations arises from the parameterisation of sub-grid scale convection. With increasing model resolution, approaching the so-called convection permitting scale, it is possible to switch off most of the convection parameterisations. A set of simulations using COSMOCLM model has been carried out at different resolutions in order to investigate possible improvements and limitations resulting from increased horizontal resolution. For our analysis, 30 years were simulated in a triple nesting setup with 50,7 and $2.8 \mathrm{~km}$ resolutions, with ERA40 reanalysis data at the lateral boundaries of the coarsest nest. The investigation area covers the state of Baden-Württemberg in southwestern Germany, which is a region known for abundant orographically induced convective precipitation. A very dense network of high temporal resolution rain gauges is used for evaluation of the model simulations. The purpose of this study is to examine the differences between the 7
\end{abstract}

\author{
G. Fosser $\cdot$ S. Khodayar \\ Institute for Meteorology and Climate Research, Karlsruhe \\ Institute of Technology, Wolfgang-Gaede-Strasse 1, \\ 76131 Karlsruhe, Germany \\ G. Fosser \\ Institute of Water and River Basin Management, Section \\ Hydrology, Karlsruhe Institute of Technology, Kaiserstraße 12, \\ 76131 Karlsruhe, Germany \\ Present Address: \\ G. Fosser $(\bowtie)$ \\ Météo France and CNRS, CNRM-GAME, 42 Avenue Gaspard \\ Coriolis, 31057 Toulouse, France \\ e-mail: giorgia.fosser@meteo.fr \\ P. Berg \\ Swedish Meteorological and Hydrological Institute, \\ Folkborgsvägen 17, 60176 Norrköping, Sweden
}

and $2.8 \mathrm{~km}$ resolutions in the representation of precipitation at sub-daily timescales, and the atmospheric conditions leading to convection. Our results show that the highest resolution of RCM simulations significantly improves the representation of both hourly intensity distribution and diurnal cycle of precipitation. In addition, at convection permitting scale the atmospheric fields related to convective precipitation show a better agreement with each other. The results imply that higher spatial resolution partially improves the representation of the precipitation field, which must be the way forward for regional climate modelling.

Keywords Regional climate model - COSMO-CLM . Convection permitting scale $\cdot$ Convection .

Atmospheric processes $\cdot$ Diurnal cycle and precipitation

\section{Introduction}

Precipitation is one of the most crucial variables to assess in a changing climate. However, it is also one of the most difficult to simulate. Although daily precipitation statistics improve with increasing spatial resolution (Boberg et al. 2009, 2010; Berg et al. 2013), problems remain with the sub-daily statistics such as the diurnal cycle (Dai and Trenberth 2004; Dai 2006). Recent investigations have shown the importance of higher temporal resolution in precipitation statistics (Haerter et al. 2010; Berg et al. 2013), especially for assessments of convective type precipitation (Lenderink and van Meijgaard 2008; Haerter and Berg 2009).

A high temporal resolution of precipitation statistics is especially important in summer when precipitation over land is often convective (Dai and Trenberth 2004; Dai 2006). In regional climate models (RCMs) convective precipitation usually occurs too early in the day and the amplitude of 
its diurnal cycle is usually overestimated (Brockhaus et al. 2008; Yang and Slingo 2001; Dai and Trenberth 2004; Dai 2006). The correct representation of convective precipitation is a very complicated task in modelling because it involves complex interactions between the surface, the boundary layer, and the free troposphere (Khodayar et al. 2013). Furthermore, vertical profiles of temperature and humidity define the convective available potential energy (CAPE; Moncrieff and Miller 1976), thereby affecting the strength of the convective systems and the associated precipitation intensities (e.g. Emanuel 1994). Since convection acts on a scale of only a few kilometres, it is necessary to use parameterisations for typical RCM simulations with grid resolutions of 10-100 km. According to Weisman et al. (1997), $4 \mathrm{~km}$ spatial resolution may be sufficient for non-hydrostatic models to explicitly represent convective systems. Previous studies (e.g. Hohenegger et al. 2008; Brockhaus et al. 2008; Bechtold et al. 2004) recognised the parameterisation of convection as a major source of uncertainties and errors in simulating the diurnal cycle of precipitation.

Increasing the spatial resolution towards convection permitting scales provides the possibility to switch off a major part of the convective parameterisations. In addition, a higher resolution model allows a better representation of orography and surface fields which are crucial for the initiation of convection in complex terrain (Hohenegger et al. 2008). Copious literature proves the added value of this spatial resolution in the representation of the precipitation field especially in cases of moist convection and/or in regions with strong orography (Langhans et al. 2013; Mass et al. 2002; Miura et al. 2007; Grell et al. 2000; Richard et al. 2007; Lean et al. 2008; Schwartz et al. 2009; Weusthoff et al. 2010; Baldauf et al. 2011; Hohenegger et al. 2008; Prein et al. 2013). Most of these studies are related to numerical weather prediction (NWP) or limited to few summers. The computational cost is high for running long-term high-resolution simulations, and there is furthermore a shortage of suitable observational datasets available for evaluation.
The goal of this paper is to investigate the possible improvements and limitations in the representation of convective precipitation resulting from increased horizontal resolution in climate model simulations. For this purpose, we compare the performance of two climatological simulations of 30 years each with the COSMO-CLM (COnsortium for Small scale Modelling model-in CLimate Model, here abbreviated CLM); one at $7 \mathrm{~km}$ (CLM7) horizontal resolution with parameterisation of convection, and one at $2.8 \mathrm{~km}$ resolution (CLM2.8) with most convective parameterisations turned off such that no sub-grid scale precipitation is calculated. A high temporal resolution and spatially dense station observational data set is used for validation. Since the main difference between the two simulations in terms of model setup resides in the convection scheme we explore the differences between the two resolutions in the representation of the conditions leading to convection in detail. In this context, the instability of the atmosphere, vertical profiles of temperature and humidity as well as cloud cover, radiation budget and triggering mechanisms are investigated. In Sect. 2, we present the investigation area and its characteristics, and in Sect. 3 we describe the model configuration for the different simulations, as well as the observational data used for validation purpose. An overview of the methods is provided in Sect. 4. In Sect. 5 we discuss the results on the representation of precipitation and the atmospheric conditions leading to convection and we end with conclusions in Sect. 6.

\section{Investigation area}

The state of Baden-Württemberg in southwest Germany contains diverse regions such as the flat Rhine valley and the Black forest with strongly varying topography (Fig. 1b), which markedly impact on the precipitation distribution in the area (Khodayar et al. 2013). In particular, the alternation of hills and valleys generates local winds (Koßmann
Fig. 1 The panels show: a the simulation domain for each step of the nesting strategy, namely $50 \mathrm{~km}$ domain (red), $7 \mathrm{~km}$ (blue), $2.8 \mathrm{~km}$ (black); b the topographical features of the simulation domain at $2.8 \mathrm{~km}$ (solid box) located in BadenWürttemberg in southwestern Germany. The dashed box indicates the investigation area common to all simulations. The blue crosses indicate the locations of the precipitation gauges
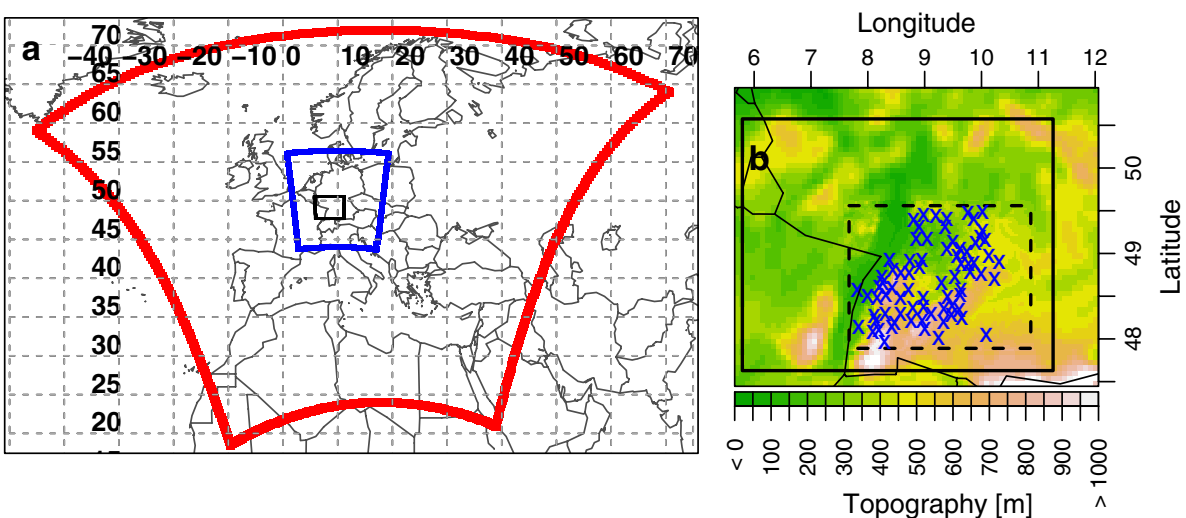
and Fiedler 2000; Kalthoff et al. 2000), which result in convergence zones over the mountain crests (Fiedler et al. 2000) and trigger convection (Meißner et al. 2007; Barthlott et al. 2006). Several campaigns, like VERTIKATOR in 2002 (e.g. Barthlott et al. 2006) and COPS in 2007 (e.g. Kottmeier et al. 2008) were conducted in this area to better understand the processes and the conditions leading to convection. The campaigns focused on summer months when convective processes are more intense in this area. In addition, this area is known for the difficulties of NWP in providing satisfying precipitation forecasts (e.g. Barthlott et al. 2010). These features make southwestern Germany a meteorologically interesting and challenging region to model orographically induced convective precipitation.

\section{Data and models}

COSMO is a non-hydrostatic local area model originally created by the German Weather Service (DWD) for weather predictions (Steppeler et al. 2003) and later adapted to perform climatological simulations by the COSMO-CLM community (Böhm et al. 2006). Using ERA40 reanalysis data (Uppala et al. 2005) as driving data for the simulations, a triple nesting procedure in rotated coordinates was employed to reach the final high resolution (Fig. 1a). The coarsest nest at $0.44^{\circ}$ resolution (circa $50 \mathrm{~km}$ ) comprises large parts of Europe $(118 \times 112$ grid points). The next finer nest (here referred to as CLM7) at $0.0625^{\circ}$ (circa $7 \mathrm{~km}$ ) covers all of Germany and the near surroundings $(165 \times 200$ grid points) and the finest nest (here referred to as CLM2.8) used here is at $0.025^{\circ}$ (circa $2.8 \mathrm{~km}$ ) and concentrates on the state of Baden-Württemberg [140 $\times 116$ grid points; similarly to Prein et al. (2013)] in southwestern Germany (Fig. 1). All simulations use 40 vertical levels and nine soil layers, and are carried out for the period 1968-1999 with the first 3 years considered as spin-up time and therefore not included in the analysis. The present study focuses on the added value of resolving convection in the representation of atmospheric conditions leading to precipitation. In this context, the coarser nest at $50 \mathrm{~km}$ resolution (see Berg et al. 2013) is not included in the current analysis.

The $7 \mathrm{~km}$ resolution is in a spatial range where larger convective processes can be resolved, while smaller ones need a parameterisation; thus, there could be an overlap between resolved and parameterised convection. Therefore, in addition to CLM2.8 and CLM7, a shorter run (1991-1999 including 1 year spin-up time), called CLM7_conv, at $0.0625^{\circ}$ was performed over the same simulation domain as CLM7, but without most of the convection parameterisations. The setup used in this study (CLM version 4.8) employs a Runge-Kutta time-stepping scheme and a delta-two-stream radiation scheme according to Ritter and Geleyn (1992) called every hour for CLM7 and CLM7_conv, and every $15 \mathrm{~min}$ for CLM2.8. Convective mass flux is parameterised in CLM7 according to the Tiedtke (1989) scheme with a moisture convergence. CLM2.8 and CLM7_conv utilise this parameterisation only for shallow convection, thus no precipitation is produced for the sub-grid. Vertical turbulent diffusion uses prognostic turbulent kinetic energy TKE (Raschendorfer 2001) including effects from subgrid-scale condensation and from thermal circulations. The Kessler scheme (Kessler 1969) is used for the calculation of grid scale clouds and precipitation and it considers the following hydrometeor species: water vapour, cloud droplets, rain, snow, cloud ice, and for CLM2.8 additionally graupel. More details of CLM can be found in Doms et al. (2011).

For the validation of precipitation we used two different observational datasets. REGNIE (REGionalisierung der NIEderschlagshöhen) is a gridded $1 \times 1 \mathrm{~km}$ precipitation data set developed by the DWD. It is based on daily measurements from around 4,000 stations throughout Germany from 1971 to the present. The gridding strategy includes corrections for orography and the orientation of the terrain in terms of wind exposure (Berg et al. 2013; Dietzer 2003; Bartels et al. 2006). Furthermore, a station dataset with 5 min resolution precipitation gauges maintained by DWD is used. The gauges use the weighting principle and have a lower measurement limit of $0.01 \mathrm{~mm}$ (Brommundt and Bárdossy 2007). The station density is generally varying with time, but peaks with a stable density for the period 1997-2004, for which 74 stations are available within the investigation area (Fig. 1b marked by x's). In order to have a consistent data set in time and space, only gauge data from this time period are used in the analysis.

\section{Method}

In order to investigate potential added values of convective resolving scale CLM2.8 versus CLM7, we proceed in two steps. First, we focus on the precipitation statistics between resolutions, and secondly, we examine the atmospheric conditions relevant for convection in order to explain the differences observed in the first part of the analysis. Most of the study is based on the sub-daily scale because a more detailed representation of the spatial pattern should go along with a higher temporal resolution. Besides a better representation of important features such as topography, the main difference among our model runs is the treatment of deep convection, which is parameterized in CLM7 and physically resolved in CLM2.8. Convection is a process lasting usually for few hours; to assess the differences 
between models and try to understand the underlying reasons a sub-daily scale is necessary.

In the investigation area, precipitation is mainly due to large-scale processes during winter, while in summer convection becomes dominant. Therefore, the first step of the analysis considers both winter and summer seasons (DJF and JJA respectively) to investigate the effects of different horizontal resolutions on precipitation occurring from different synoptic scale. Bias maps and probability distribution plots as well as diurnal cycles are used to evaluate the differences in precipitation between the CLM7 and CLM2.8 simulations. Berg et al. (2012) found that CLM7 produces too much drizzle, which leads to an underestimation of dry days (i.e. days with precipitation less than $1 \mathrm{~mm} /$ day) and to an overestimation of low intensities. Therefore, frequency of dry periods and duration of events are also considered in our study.

CLM7, CLM2.8 and REGNIE have different grid resolutions. Therefore, a conservative remapping of CLM2.8 and REGNIE data to the CLM7 grid was necessary to compare the outputs among each other and on equal terms (Berg et al. 2013). The CLM7 resolution is maintained for all data and all analyses. To compare model outputs with station data, the nearest grid point is selected in order to reduce sampling biases in this region of diverse landscape. The same strategy is also applied with the REGNIE dataset. Sensitivity tests were performed for both CLM2.8 and CLM7 on the specific grid point employed. Using the average over five grid points instead of only a single grid point brings a reduction in mean intensity, to be expected when averaging (not shown). However, the shape of the probability distribution and diurnal cycle is kept unchanged, indicating that the results are robust to these types of changes.

Since the station data are available for the 8 year period 1997-2004, which does not completely overlap with the simulated years (1971-1999), the sensitivity of the model and REGNIE results to the chosen time period is also considered. For the REGNIE data set in Fig. 3 and the model simulations in Figs. 3 and 5, the average of their curves for the time periods 1976-1983, 1984-1991, 1992-1999 is plotted. The sensitivity analysis is carried out computing confidence intervals with a bootstrap approach (Efron and Tibshirani 1993) by randomly selecting eight of the years between 1971 and 1999 a large number of times. The standard deviation of these surrogate data is multiplied by 1.64485 to arrive at the $95 \%$ confidence levels plotted in Figs. 3 and 5 as dashed lines and shaded areas. The signal was found robust for around 500 surrogates. In addition, REGNIE data well compare to station data over the overlapping period 1997-2004 on daily base (not shown). Hourly data are less likely to present any significant differences between the periods due to a low signal-to-noise ratio. Thus, the curves for the REGNIE data set in Fig. 3a, b provides a good measure of differences between the periods for all intensities. Note that the paper focuses mainly on the general shape of the intensity distributions (Fig. 3) and the diurnal cycle of precipitation (Fig. 5). For the latter, we find robust results for the timing of the peak and the general shape even for shorter intervals (not shown). Thus a qualitative comparison is certainly possible.

The second step of the analysis aims at investigating differences in the atmospheric conditions leading to precipitation between CLM2.8 and CLM7. Since the main distinction between CLM7 and CLM2.8 is the treatment of deep convection (parameterized or physically resolved), the analysis concentrates on convective precipitation and is thus restricted to the summer period JJA, when convective precipitation is most frequent. In this context, the CLM7_conv simulation was performed to evaluate the influence of the parameterisation at CLM7 resolution on the representation of the atmospheric fields. Therefore, the results from the CLM7_conv simulation only appear in the analysis of the diurnal cycle of precipitation and other selected variables describing the atmospheric conditions.

Although there is no unique recipe for convection, some ingredients should be in place, namely an unstable atmosphere, enough atmospheric moisture and a triggering mechanism allowing the release of the potential energy. In the area under investigation, orography plays a key role in the initiation of convection. In summer mainly "boundarylayer forced" convection occurs (Kottmeier et al. 2008). In addition to the investigation of the atmospheric temperature and water vapour content conditions, simulated CAPE and convective inhibition (CIN; Colby 1984) are used as indicators of the atmospheric degree of stability/instability and thus the potential for convective processes. Note that the analysis is performed on climatological base, meaning that the atmospheric variables are averaged for JJA over 30 years including all weather conditions. Moreover, all the grid points are considered since there is no comparison with observations. The CLM model calculates CAPE and CIN in each grid point independently according to the temperature and moisture of the ascending parcel (parcel theory) and uses the $50 \mathrm{hPa}$ mixed layer (ML) method to compute the air parcel rising. Furthermore, CAPE depends on both humidity and temperature (Emanuel 1994), thus these variables are analysed in more detail using vertical profiles and diurnal cycles. The lifted condensation level (LCL) is calculated to assess the impact of the different boundary layer conditions on the level of base cloud formation. The level of free convection (LFC) is considered in order to estimate how strong the triggering mechanisms for the release of CAPE should be. The investigation also considers cloud cover at both low and middle level (respectively in the range 0-2 and 2-7 km). Differences in the spatial distribution and percentage coverage 

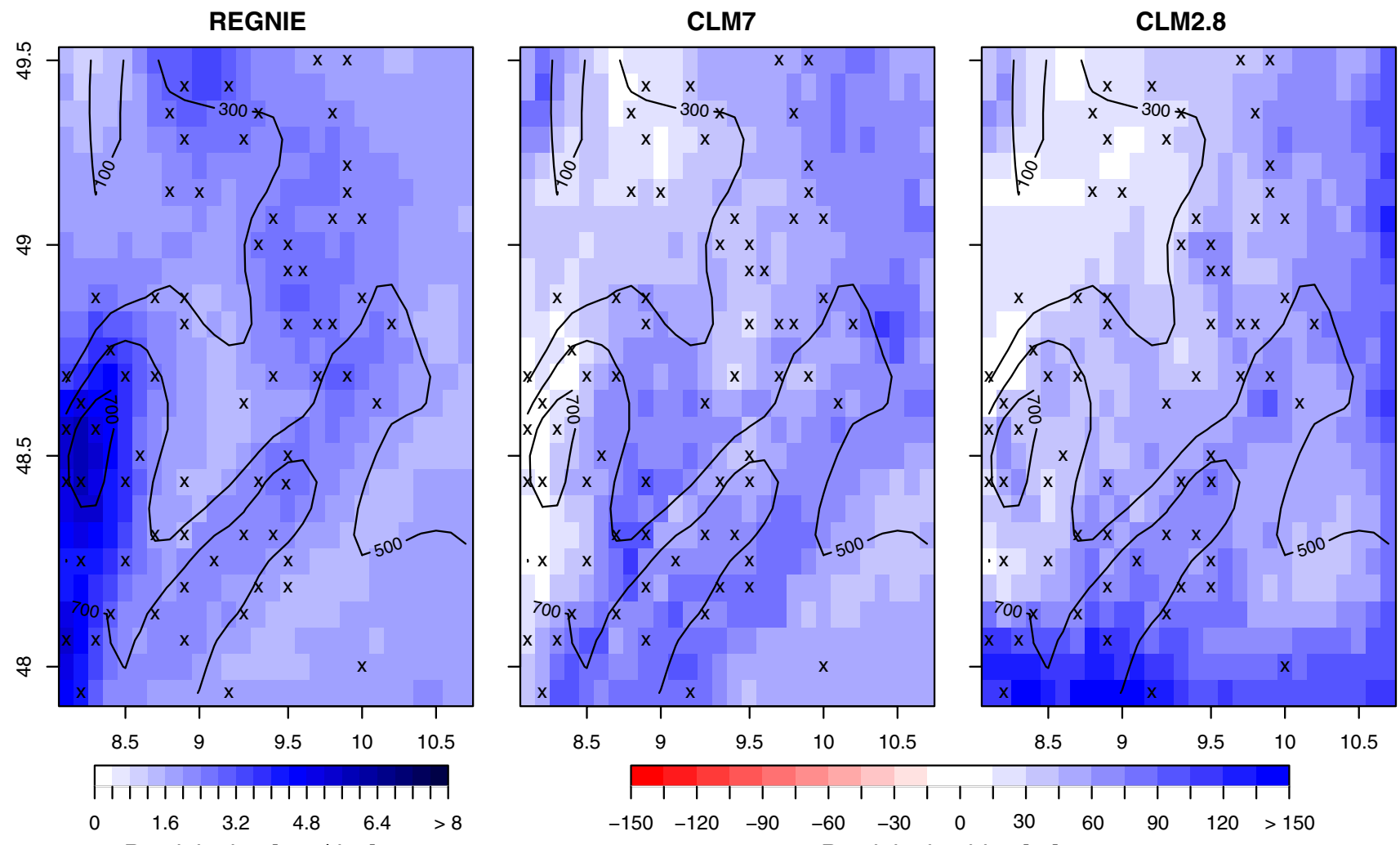

Precipitation [mm/day]
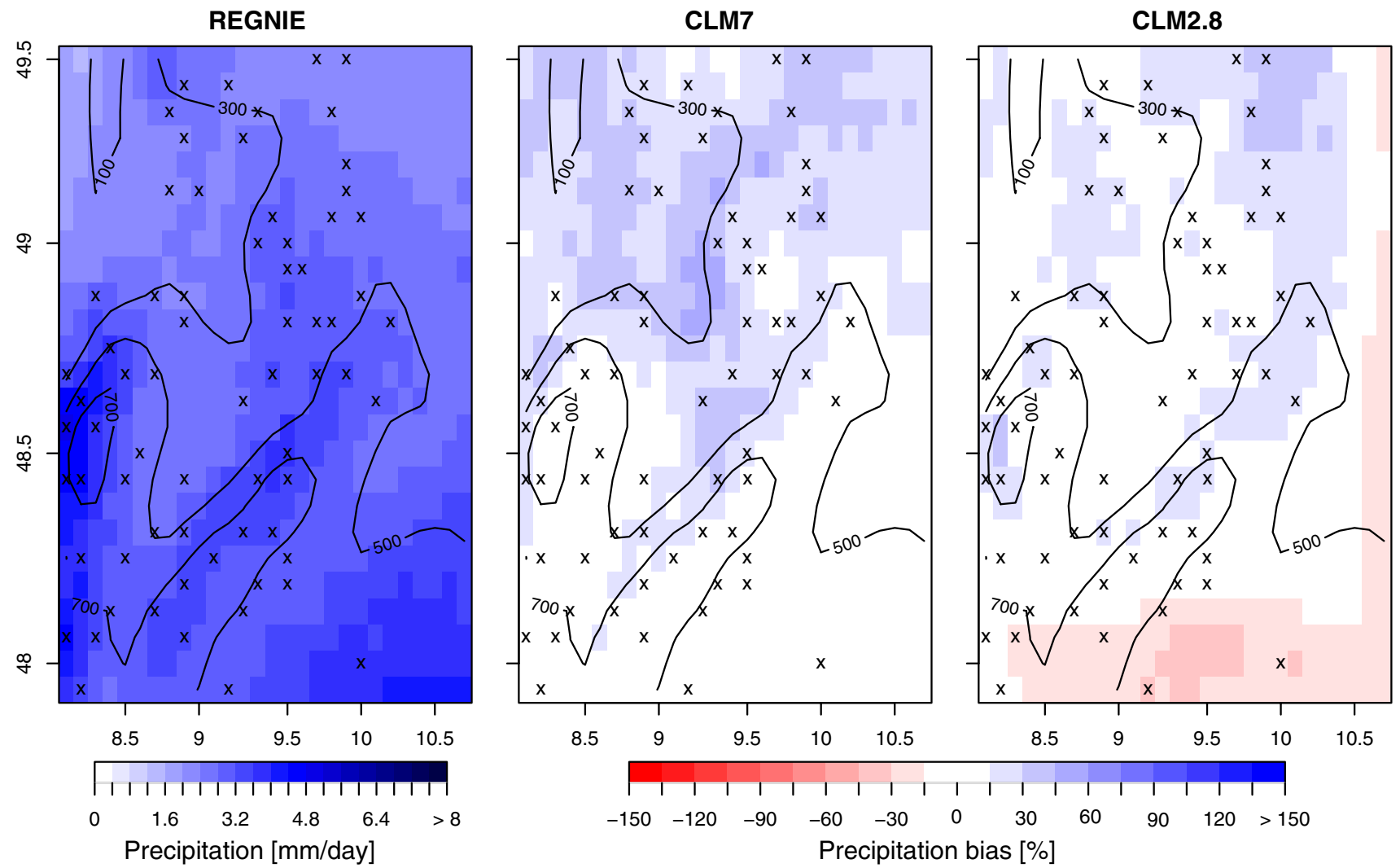

Fig. 2 Spatial distribution of daily mean precipitation from REGNIE dataset (left) in DJF (top) and JJA (bottom); differences in daily mean precipitation between CLM7 and REGNIE (middle) as well as between CLM2.8 and REGNIE (right). The contours indicate the topography (in meters) and $x$ indicates the precipitation gauges used for subsequent analysis 
Fig. 3 Probability density function of precipitation intensities multiplied by intensity for each bin for daily (top) and hourly temporal resolution (bottom) for DJF (left) and JJA (right). The dry day/hour $(<1 \mathrm{~mm} /$ day or $<0.1 \mathrm{~mm} / \mathrm{h}$ ) probability is given in parenthesis in the legends. Note the logarithmic vertical axis. The $95 \%$ confidence intervals based on the time-period (see Sect. 4) are indicated with dashed lines for the model and REGNIE data
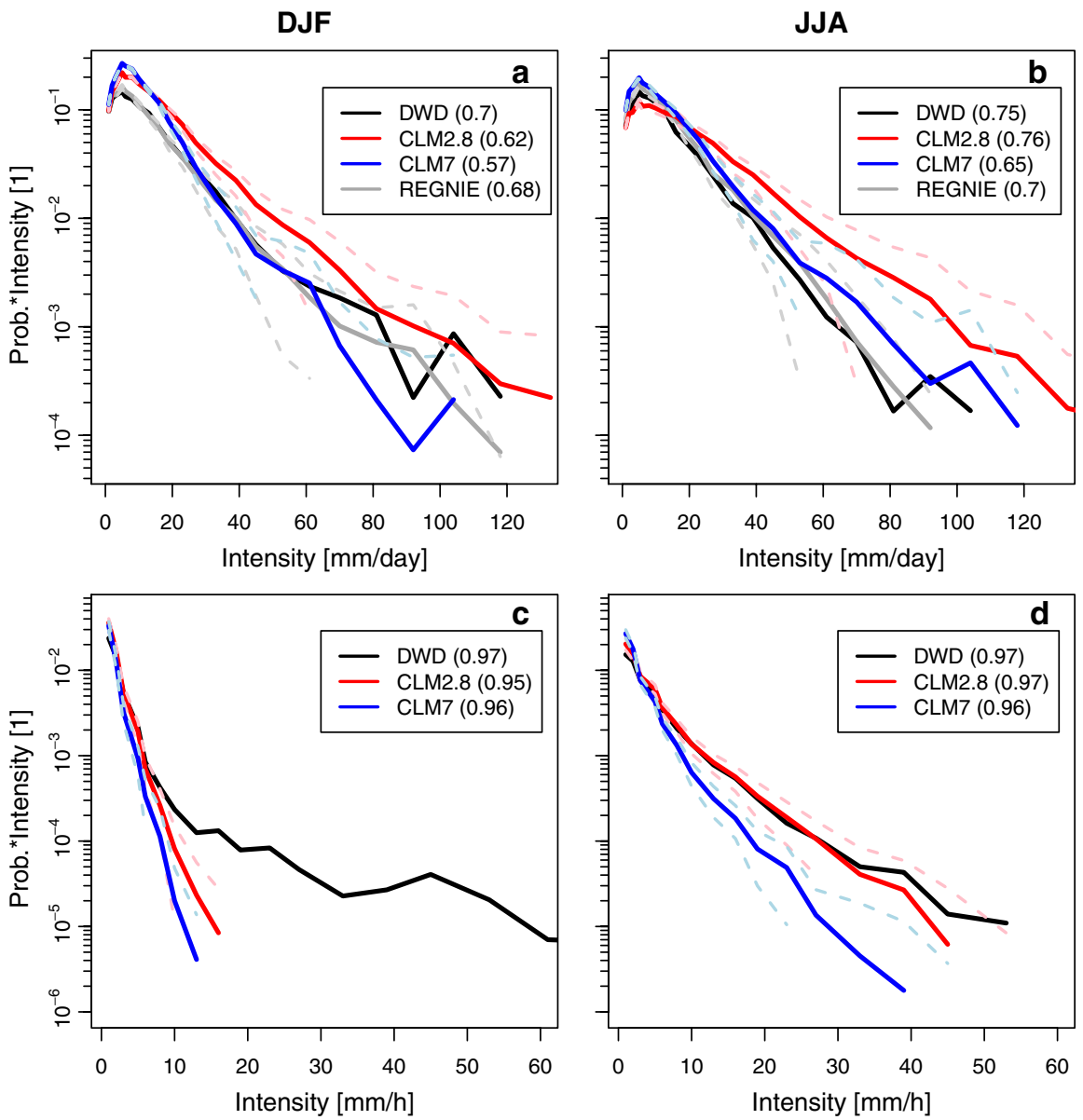

of clouds in the model simulations could lead to important changes in the atmospheric conditions, such as variation in radiation, temperature and humidity. In addition to enough moisture supply and an unstable atmosphere, a triggering mechanism is necessary for convection. Several studies already pointed out the fact that increasing spatial resolution leads to a better representation of topography, hence wind circulation patterns and resulting vertical velocity (e.g. Barthlott et al. 2006). Since orographic lifting plays a crucial role in triggering convection over complex terrain, the differences between model resolutions in the simulation of the vertical velocity field are assessed in this investigation.

\section{Results and discussion}

Hereinafter, the results are presented in two steps following the same structure as presented in the method section, since different methodologies are applied for each of them. The first subchapter focuses on the comparison between the model simulations (CLM2.8 and CLM7) and observations (REGNIE and rain gauges) in terms of precipitation statistics for both summer and winter. The second examines the atmospheric conditions in JJA relevant for the occurrence and the development of convection.

\subsection{Precipitation statistics}

\subsubsection{Spatial mean}

The DJF and JJA mean precipitation of the first nest $50 \mathrm{~km}$ CLM simulation, as well as the CLM7 simulation, suffer from a wet bias over Germany as shown in Berg et al. (2012). In this region, on average, the bias is larger in winter than in summer, and also shows a gradient over Germany with wetter conditions in the north-east than in the south-west, due to a circulation bias in the first nest simulation. Figure 2 shows the seasonal precipitation bias of the CLM7 and CLM2.8 simulations for the current investigation domain in comparison to the REGNIE data set for the period 1971-1999. In winter, there is a strong wet bias up to $150 \%$ for both simulations with higher values in regions of steep orography for CLM2.8. The summer bias is weaker, with values lower than $60 \%$ for CLM7. For CLM2.8 the wet bias is even lower but with additional dry 
bias in the southeast of the domain. Generally, the bias patterns are similar between the two simulations.

\subsubsection{Intensity distributions}

The distributions of daily precipitation intensities are shown in Fig. 3 (top). Note that here only the closest grid points of the model simulations and REGNIE to the precipitation gauges (marked by x's in Figs. 1b, 2) are shown (see Sect. 4). Besides a slight underestimation of the probability of dry days in summer (Fig. 3a, b in brackets in the legend), stations and REGNIE data agree well for lower intensities, especially in winter. Above $20 \mathrm{~mm} /$ day, the station data is always within the confidence intervals of REGNIE. Note the fast growth of the confidence intervals, based on the time period studied, with increasing intensity as shown with dashed curves in the plots. In winter, CLM7 performs well for intensities above $30 \mathrm{~mm} /$ day, but overestimates intensities below, which consequentially leads to an underestimation of dry days. These biases are also present in summer, however, not as accentuated. CLM2.8 performs better for the dry day probability compared to CLM7, with values comparable to observations in summer. In winter, CLM2.8 overestimates probabilities for all intensities above $1 \mathrm{~mm} /$ day, while in summer it underestimates (overestimates) probabilities below (above) about $20 \mathrm{~mm} /$ day. There are, thus, large differences in the intensity distributions between the two simulations, although the mean intensities are similar (not shown).

At the hourly temporal resolution, the intensity distributions change character (Haerter et al. 2010). The station data show a probability density function with higher intensities in summer compared to winter, see Fig. 3 (bottom). Note that the seemingly extreme tail of the station curve in winter above about $10 \mathrm{~mm} / \mathrm{h}$ is due to only a few stations with some extreme events, and is highly uncertain. Both model simulations perform well in the probability of dry hour, i.e. hours with precipitation below $0.1 \mathrm{~mm} / \mathrm{h}$. In winter, both CLM7 and CLM2.8 are underestimating (overestimating) intensities above (below) $5 \mathrm{~mm} / \mathrm{h}$. In summer, CLM2.8 clearly outperforms CLM7, with probabilities close to those observed for intensities above about $5 \mathrm{~mm} / \mathrm{h}$, while CLM7 underestimates (overestimates) probabilities above (below) $5 \mathrm{~mm} / \mathrm{h}$.

Interestingly, the CLM2.8 simulation performs well on the hourly timescale, especially in summer, but poorly on the daily time scale, while the contrary applies to CLM7. At the same time, the dry day and dry hour probabilities are reasonable. It is suspected that the model alternates wet and dry hours differently from the observations over the course of several days, thus leading to a different precipitation sum on daily base. To investigate this hypothesis, we calculate the durations and the amounts of the precipitation events in the models and in the observations using the data at an hourly temporal resolution. For this type of analysis it is necessary to have the same number of years for both observations and simulations; thus, the JJA period 19921999 and 1997-2004 were respectively selected to create Fig. 4. Note that similar findings are found also for different time periods of the models (not shown). An event starts when the intensity is larger than $0.1 \mathrm{~mm} / \mathrm{h}$ and stops when it drops below this limit. Figure 4a shows the number of events as a function of their duration, and in the legend reports the total number of events for the selected 8 year period. Clearly, both CLM7 and CLM2.8 are overestimating the duration of the events. Since the dry hour probability is simulated well by the model at both resolutions, the longer duration are caused by an incorrect clustering of the wet hours on the events base and consequentially on daily base. Thus, hourly statistics are well reproduced, but the daily statistics are not well represented as the hours cluster over different days. CLM7 shows too frequent short duration events (Fig. 4a); CLM2.8 is closer to observations regarding the total number of events, but is strongly overestimating not only the duration of the events, but also their total amount of precipitation (see Fig. 4b). The latter might, however, be directly related to the longer durations.

Figure $4 \mathrm{c}, \mathrm{d}$ shows scatter plots of the precipitation amount per each event as a function of duration in JJA. The lines in the plots indicate lowess curves (Cleveland and Devlin 1988) fitted to the data. A trivial 1-1 relationship of linear increase of amount with increased duration is shown as a dashed grey line. The observations have a steeper increase of amount versus duration, thus the average intensity of the events increases with longer duration. Such behaviour can be expected from convective precipitation, whereas stratiform precipitation should have a weaker gradient, especially when considering that also non-precipitating times are included in the hourly statistics (although not resolved by the hourly output frequency of the model). CLM2.8, and especially CLM7, show weaker gradients. A possible explanation for this behaviour is connected with low intensity precipitation between 0.1 and $5 \mathrm{~mm} / \mathrm{h}$, which are overestimated by the model (Fig. 3d). If a given event is surrounded by low intensity precipitation above $0.1 \mathrm{~mm} / \mathrm{h}$, this will both increase the duration of the event (Fig. 4a) and decrease the mean intensity of the event (Fig. 4c, d). For the daily temporal resolution, the intensity will increase as there are less zerointensities surrounding the events, thus explaining the overestimation of intense events for CLM2.8 in Fig. 3 (top right).

\subsubsection{Diurnal cycle}

The observations have a distinct diurnal cycle in both winter and summer. In winter (Fig. 5a), there is a peak around 09:00, but otherwise no significant structures, while in 

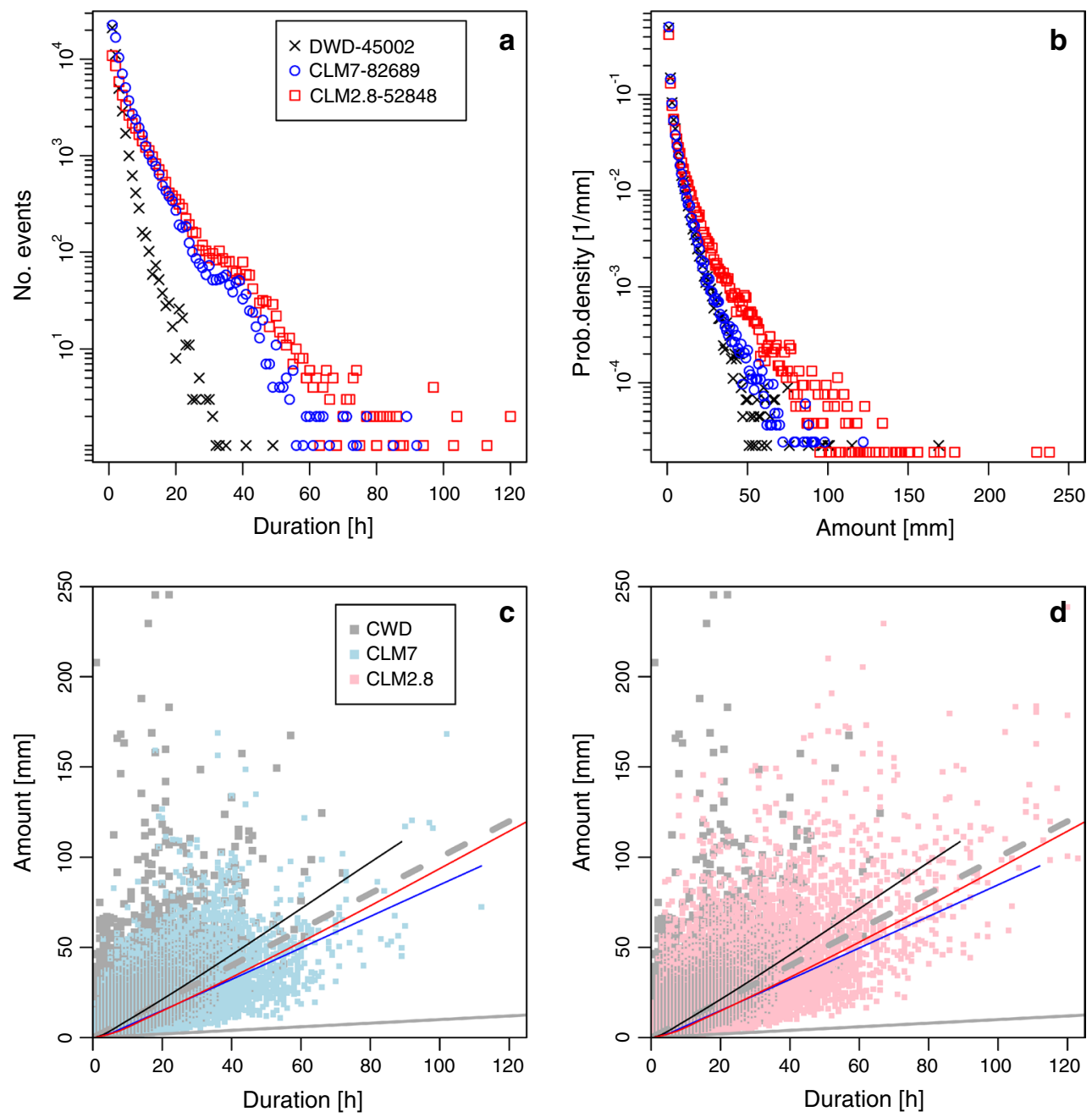

Fig. 4 The panels show: a the distribution of the event durations of CLM7, CLM2.8 and the observations in JJA based on hourly data. The numbers in the legend indicate the total number of events for each data set; $\mathbf{b}$ the probability density function of precipitation amounts from individual events; $\mathbf{c}$ and $\mathbf{d}$ scatter plots of duration ver-

sus amount. The lines indicate the lowess curves fitted to the data. The dashed grey line is the 1-1 fit. Note that the lines are the same in both $\mathbf{c}$ and $\mathbf{d}$, but the scatter data are shown separately for CLM7 in $\mathbf{c}$ and CLM2.8 in $\mathbf{d}$ for reasons of clarity. The solid grey line indicates the lowest possible value, given the definition of event

Fig. 5 The panels show the diurnal cycle of precipitation for CLM2.8 (red), CLM7 (blue), CLM7_conv (green) and observations (black) for: a DJF and b JJA. The resolved and parameterised components for the CLM7 simulation are presented as dashed and dotted blue curves respectively. The $95 \%$ confidence intervals based on the time-period (see Sect. 4) are shaded
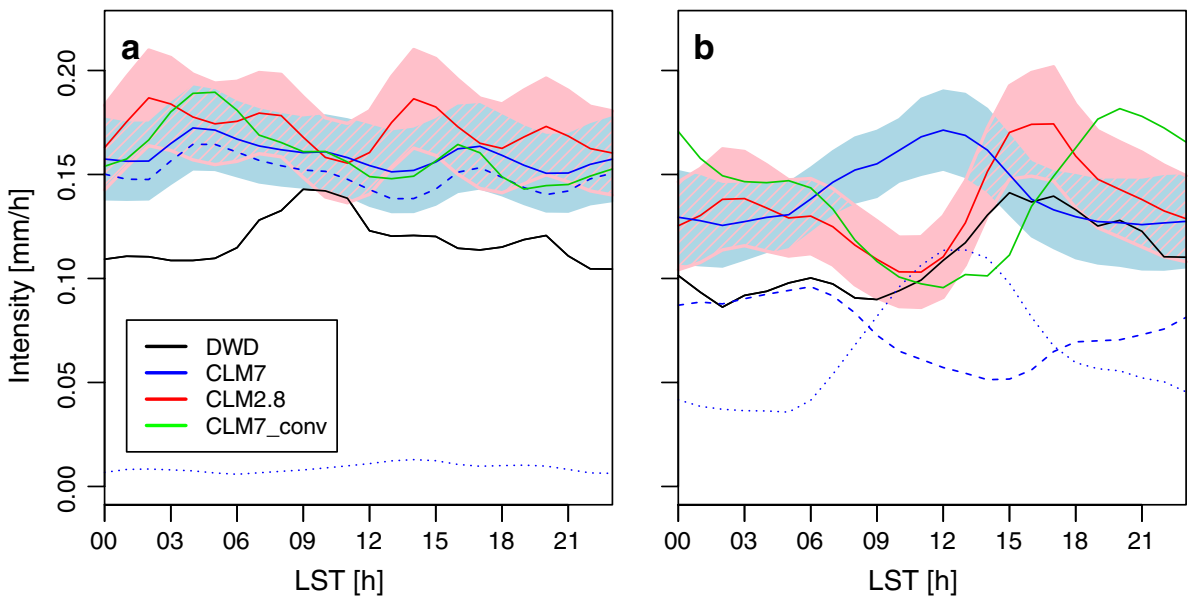
summer (Fig. 5b) there is a main peak around 15:00-17:00 and a weaker secondary peak at 06:00. Neither of the models captures the morning peak in winter. In summer, CLM7 produces only one peak, with maximum amplitude at 12:00. Since CLM7 uses a parameterisation for convection, it is possible to plot the grid resolved and parameterised precipitation components separately. It is then clear that the convective parameterisation is solely responsible for the midday peak (dotted blue line in Fig. 5b), and furthermore overlaps the morning peak of the grid resolved component (dashed blue line). The CLM7 simulation is in a grey zone where it is not obvious how resolved and parameterised convection coexist. Therefore, to test whether the parameterisation interferes with the grid resolved component negatively, a shorter simulation (1992-1999), called CLM7_conv, was performed with the Tiedtke scheme switched off except for shallow convection, as in the CLM2.8 settings. The result from this 8 year integration is shown as a green line in Fig. 5b. The peak in the diurnal cycle occurs too late in the evening, at around 19:00, and slightly overlaps with the morning peak, similarly to what found by Weisman et al. (1997). Two conclusions can be drawn: firstly, the CLM7 resolution is too coarse to properly resolve convection, and secondly, the too early triggering of the convection scheme in CLM7 interferes destructively with the grid resolved convection.

In summer, CLM2.8 produces a main peak at 15:00-17:00 (Fig. 5b), in good agreement with the observations, and a secondary peak occurs around 02:00-03:00. Thus, CLM2.8 sensibly improves the representation of the diurnal cycle in comparison with coarser resolution, creating a pattern, which is similar in shape to observations in summer. Particularly relevant is that CLM2.8 correctly simulates the time of maximum convection, which is the main failure of CLM7. To understand the reasons behind this, we examine in more detail how the models simulate the atmospheric conditions leading to convective precipitation, starting from the instability of the atmosphere, proceeding with the analysis of the vertical profiles of temperature and humidity, cloud cover, radiation and finishing with triggering mechanism of convection. The focus is on the comparison between CLM2.8 and CLM7 while the use of CLM7_conv is limited to help understanding the effect of the parameterisation on the results. In the area under investigation, deep convection occurs mainly in the summer early afternoon when the atmosphere is most unstable and it is almost negligible in the winter period. Therefore, the analysis in the next section is focused only on the summer period.

In spring (MAM) and autumn (SON) precipitation is due to a mixture of local and large scale forcing conditions and thus it is difficult to clearly identify the added values gained in switching off the convective scheme at finer spatial resolution. Nevertheless, a quick overview of the diurnal cycle in spring and autumn is provided for completeness (not shown). In spring, the observational diurnal cycle of precipitation shows a similar picture to the summer, but the intensities are reduced and the maxima occur later. CLM7 postpones the maximum and reduces the peak intensity, but still overestimates the precipitation compared to observations. CLM2.8 presents the same shape as in JJA but the maximum intensities highly overestimate observations. In autumn, the observational diurnal cycle changes completely showing the main maximum at 4:00 and a secondary one around 10:00. CLM2.8 interprets the diurnal cycle quite well, although it slightly underestimates the morning maxima. CLM7 shows only one maximum at 6:00 which is of lower amplitude than either of the observed morning maxima. The differences between the two resolutions are much reduced in this season but are similar to summer.

\subsection{Atmospheric conditions relevant for the occurrence of convective precipitation}

\subsubsection{Precipitation and convection-related indices}

The initiation of deep convection requires an unstable atmosphere as well as a trigger mechanism, which allows the release of the available energy for convection (Khodayar et al. 2010); this is also true in model simulations of precipitating convection (Khodayar et al. 2013). CAPE and CIN are well-known convective indices used respectively to assess the atmospheric potential to convection and the opposition of the atmosphere to the initiation of convection. Figure 6a shows the diurnal cycle of CAPE and CIN for each one of the model simulations. CAPE values are low in comparison to convective event studies (e.g. Barthlott et al. 2006) because they are a mean over 30 years including all-weather conditions. Note that we did not make use of observations in this step of the analysis because no adequate observational data set was available. However, Brockhaus et al. (2008) showed for one selected station in Switzerland that the Tiedtke scheme represents the shape and the amplitude of diurnal cycle of CAPE well in comparison with observations both at 00:00 and 12:00 in the 6 year JJA. Both CLM7 simulations as well as CLM2.8 present a similar diurnal cycle for CAPE and CIN, consistent with previous studies at $50 \mathrm{~km}$ resolution (Brockhaus et al. 2008); CAPE gradually increases from the early morning and it decreases again after 18:00. On the contrary, CIN is strongly negative during night and early morning; close to zero between 9:00 and 15:00, and slowly decreasing again after this time to values down to $-300 \mathrm{~J} /$ $\mathrm{kg}$. Note that lower value of CIN indicates higher atmospheric inhibition. High CAPE values indicate atmospheric instability, thus, atmospheric conditions prone to deep convection and consequent heavy precipitation. Statistically one would expect to have a high CAPE ahead of the maximum precipitation in the diurnal cycle. This phenomenon 
Fig. 6 All panels show the diurnal cycle for CLM2.8 (red), CLM7 (blue) and CLM7_conv (green) in JJA. The variables represented are respectively: a CAPE (solid line) and CIN (dashed line); b cloud cover at low (solid line) and medium level (dashed line); c averaged surface net shortwave and longwave radiation (solid and dashed line respectively), and d surface shortwave radiation components, diffusive (solid line) and direct (dashed line). Note that radiation is positive when directed downward. The model data are output every $3 \mathrm{~h}$ for variables in panels $\mathbf{a}, \mathbf{b}$, and every hour in panels $\mathbf{c}, \mathbf{d}$
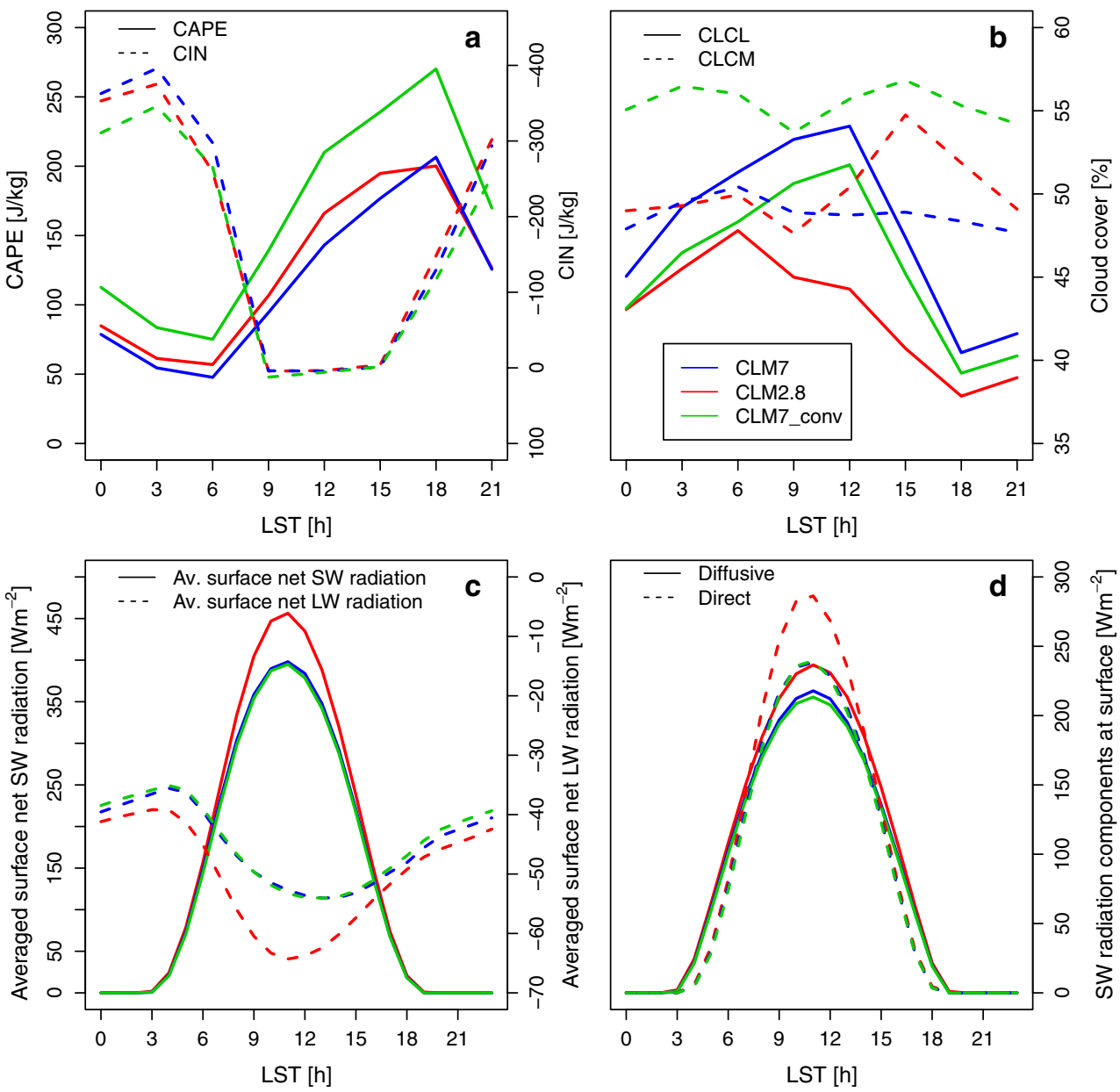

is well captured by CLM2.8, which shows the CAPE daily maximum at 15:00-18:00 and the convective precipitation maximum at 15:00-17:00.

CLM7 exhibits maximum instability around 18:00, which is too late when compared with the simulated diurnal cycle of precipitation (Fig. 5). Thus, CLM7 shows a maximum in precipitation $6 \mathrm{~h}$ before the CAPE maximum. In CLM7_conv the maximum instability occurs just before its precipitation maximum, but CLM7_conv strongly misrepresents the precipitation diurnal cycle in comparison with observations. Thus, the expected relationship between the atmospheric instability maximum and consequent convective precipitation occurrence is observed only when convection is not parameterised. CLM7 resolution clearly needs a parameterisation in order to correctly represent convective processes, which occur at smaller spatial scales, however, the currently used Tiedtke scheme cannot compete with convection permitting scale.

\subsubsection{Temperature and humidity}

The evolution of CAPE and CIN strongly depends on the atmospheric temperature and moisture, particularly on their distribution within the boundary layer (Brooks et al. 1993; Crook 1996; Weckwerth 2000; Khodayar et al. 2010). Thus, the temporal and spatial distribution of these variables is investigated in detail for both resolutions. The diurnal evolution of these variables at $\sim 950$ and $\sim 850 \mathrm{hPa}$ is similar for both simulations (not shown), but differs in magnitude. At $\sim 950 \mathrm{hPa}$ temperature and specific humidity increase from 06:00 to 12:00 and then remain constant until 18:00 being CLM7 wetter and cooler. At $\sim 850 \mathrm{hPa}$, temperature rises uniformly from 06:00 leading to a moistening of the atmosphere with CLM7 being drier and cooler. Maximum differences between early morning and evening are in the order of $0.4 \mathrm{~g} / \mathrm{kg}$ in specific humidity and $3{ }^{\circ} \mathrm{C}\left(2{ }^{\circ} \mathrm{C}\right)$ in temperature at $\sim 950 \mathrm{hPa}(\sim 850 \mathrm{hPa})$. $\mathrm{CAPE}$ increases during daytime in agreement with temperature and specific humidity variations, especially at the $850 \mathrm{hPa}$. At this level, CLM2.8 is systematically warmer and wetter.

The vertical profiles of humidity and temperature (Fig. 7a, b) show that in the lower boundary layer CLM2.8 is drier and warmer than CLM7, both in the midday (12:00) and evening (18:00) periods. The temperature and moisture differences between the two resolutions are 
Fig. 7 The panels show: a and b the skew $\mathrm{T}$ plots and vertical profiles of specific humidity at respectively $12: 00$ and 18:00 for CLM2.8 (red), CLM7 (blue) and CLM7_conv (green) in JJA. Horizontal lines show the lifted condensation level (LCL, dashed line), level of free convection (LFC, solid line) and equilibrium level, when possible (EL, dotted line). Panel c shows the diurnal cycle of the integrated water vapour
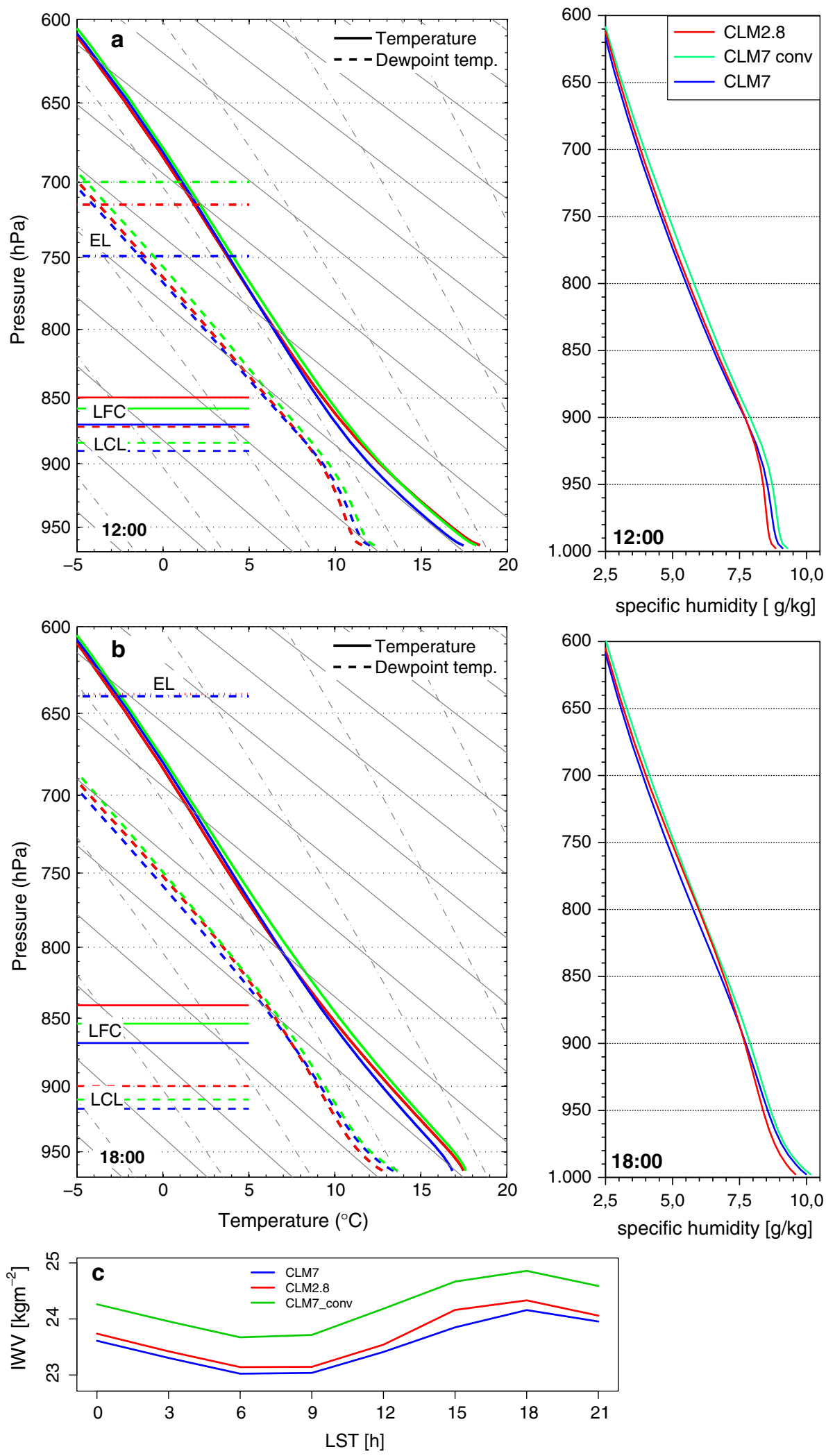

larger near the surface $\left(\sim 1{ }^{\circ} \mathrm{C} / 0.4 \mathrm{~g} / \mathrm{kg}\right)$ and they reduce gradually above. Above $900 \mathrm{hPa}, \mathrm{CLM} 2.8$ becomes wetter that CLM7, but the difference between them is limited to a maximum of $0.2 \mathrm{~g} / \mathrm{kg}$ and disappears above $600 \mathrm{hPa}$. The moisture difference in the lower boundary level is compensated in the upper layers of the atmosphere since 
Fig. 8 Spatial distribution of mean vertical wind in JJA for CLM7 (top), CLM7_conv (middle) and CLM2.8 (bottom). The selected model levels correspond approximately to a pressure of $\sim 850 \mathrm{hPa}$ (left) and $\sim 950 \mathrm{hPa}($ right $)$. The contour lines represent the orography of the area
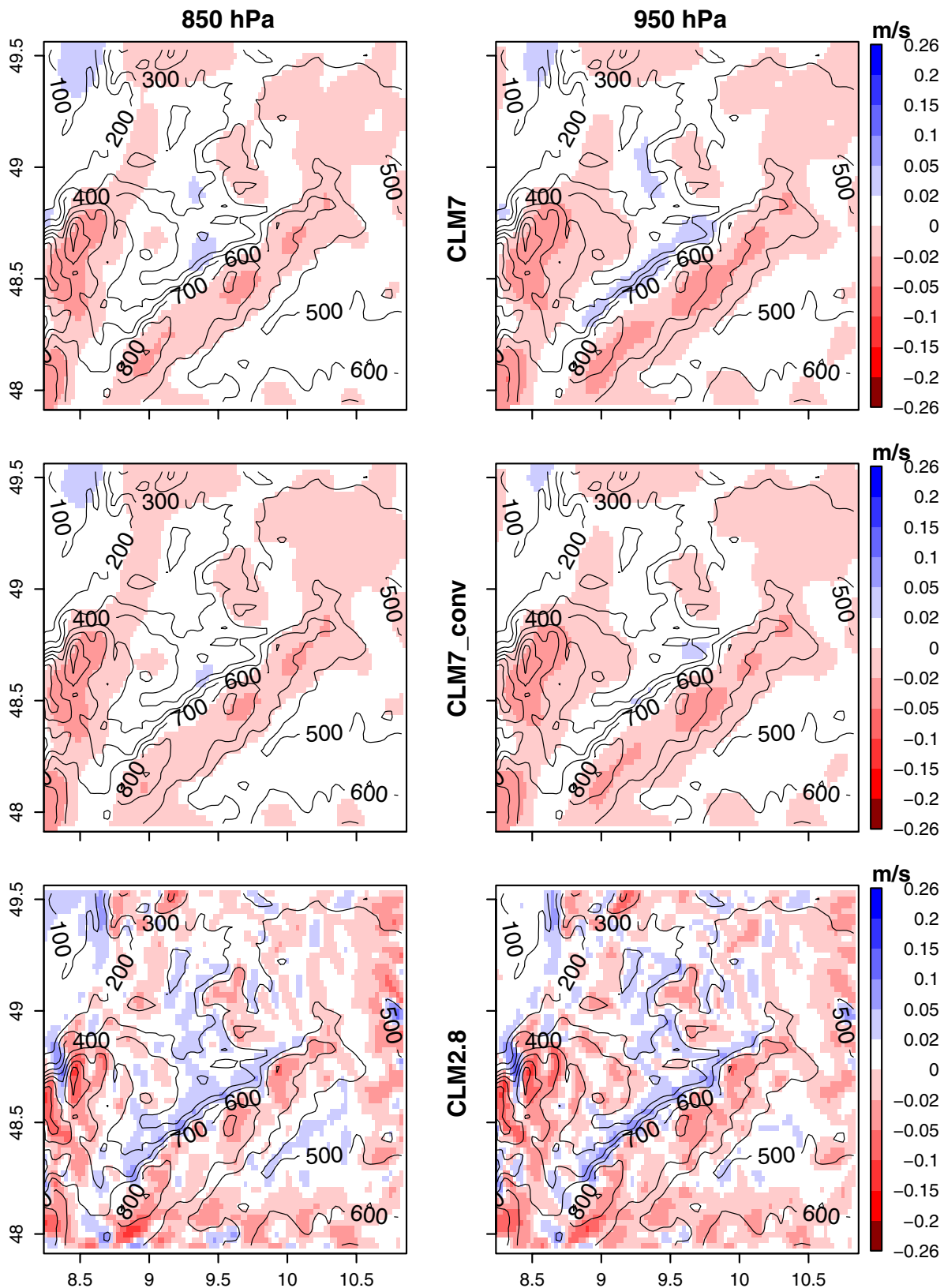

almost no differences exist in terms of integrated water vapour between the two simulations (Fig. 7c). Nevertheless, the differences in the vertical distribution of temperature and moisture, particularly in the boundary layer, impact on the atmospheric conditions and thus in CAPE and CIN, which provide information about the atmospheric instability and inhibition conditions in each simulation. CLM7_conv is systematically wetter than the other simulations, thus exhibiting higher integrated water vapour values (Fig. 7c); it is also warmer, consequently showing a more unstable atmosphere with higher CAPE values (Fig. 6a).

\subsubsection{Cloud cover and radiation}

The variations in temperature and humidity among simulations lead to differences in the vertical distribution of: the level of base cloud formation, LCL; the level of free convection, LFC (from where the atmospheric parcels freely rise); and the equilibrium level (EL), or limit of convection (Fig. 7a, b). The wetter and cooler boundary layer of CLM7 simulation results in lower LCL and LFC, in comparison with CLM2.8. The latter conditions affecting CLM7, in addition to lower EL, could result in clouds forming more easily, probably accompanied by low 
intensity precipitation. The continuous formation of clouds does not allow the increase of temperature and humidity in the boundary layer, thus inhibiting deep convection and consequent heavy precipitation; this could be one of the reasons of the drizzle problem affecting CLM7 (Fig. 4). The higher LCL and LFC in CLM2.8 indicate that the triggering mechanism needs to be stronger in order to lift the atmospheric parcels to the LFC. The vertical distribution of the LFC and EL and their temporal variation, higher EL at 18:00 than 12:00, agree with the diurnal cycle of CAPE shown in Fig. 6a.

The above-described differences are reflected in the extent of cloud cover in the atmosphere. CLM differentiates between low, medium and high clouds. The higher LCL and LFC of CLM2.8, with respect to the CLM7 runs, result in a reduced cover of low level clouds with a maximum difference of circa 10\% units at 12:00 (Fig. 6b). A noticeable increase in mid-level clouds is observed in CLM2.8 at about 15:00, which could be indicative of deeper convective clouds in this simulation. Note that CAPE and precipitation maxima are found in the time period between 15:00 and 17:00. Baldauf et al. (2011) found that nocturnal boundary layer clouds are responsible for simulated drizzle at night and consequentially for an excess of precipitation. In this context, the reduced cloud cover in CLM2.8 at night could be responsible for the attenuation of the drizzle problem.

The cloud coverage could, directly or indirectly, impact on the precipitation distribution in our simulations. For example, modifications of radiation fluxes can affect the diurnal cycle of near-surface temperature (in terms of both timing and intensity). This would lead to changes in the stability of the atmosphere, which could even result in suppression of convective processes. However, an overestimation of cloud cover could be also responsible for the well-known CLM underestimation (overestimation) of shortwave (longwave) net radiation (Jaeger et al. 2008). Note that longwave radiation has negative sign; hence, an overestimation would be compensated by more negative values of longwave radiation. Figure $6 \mathrm{c}$ shows that in CLM2.8 the representation of both radiation net components is improved, with respect to the findings of Jaeger et al. (2008), through an increase (decrease) of shortwave (longwave) net radiation in comparison to CLM7. The findings are in good agreement with Langhans et al. (2013). The increase in shortwave net radiation is linked to a strengthening of both diffusive and direct shortwave radiation (Fig. 6d). A higher direct radiation could be related to the reduced cloudiness at 12:00 in CLM2.8 in comparison to CLM7 (Fig. 6b). Nevertheless, the presence of an additional hydrometer species (graupel) in CLM2.8, which is not taken into account by the radiation scheme, could also contribute to this effect.

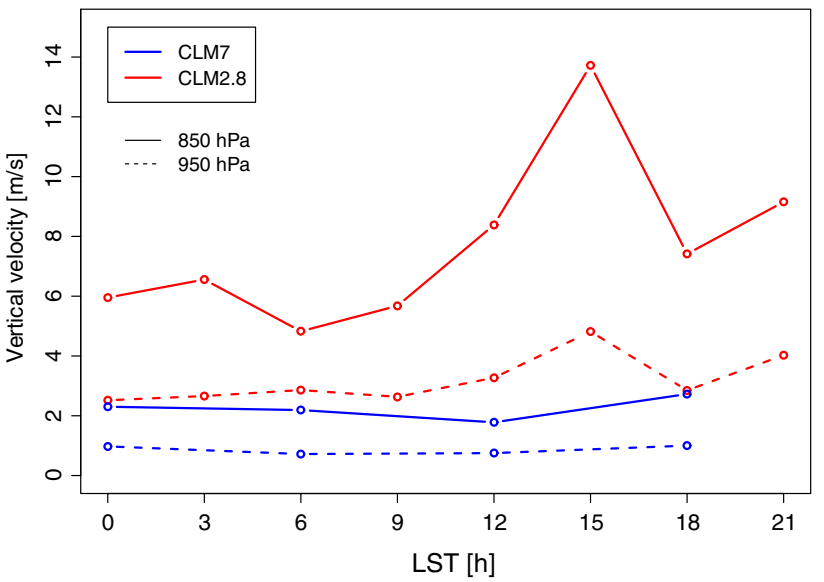

Fig. 9 Diurnal cycle of instantaneous vertical wind maxima over the investigation area at $\sim 850 \mathrm{hPa}$ (solid line) and $\sim 950 \mathrm{hPa}$ (dashed line) in JJA for CLM2.8 (red) and CLM7 (blue). Note that the data are output every 6 and $3 \mathrm{~h}$ for respectively CLM7 and CLM2.8

\subsubsection{Upward motion}

In addition to the atmospheric conditions, the existence of a triggering mechanism has been investigated. The spatial distribution of the vertical velocity, $w$, is examined in different model levels (Fig. 8). Those follow the terrain and they approximately represent, in our case, the pressure levels of $\sim 950, \sim 850$ and $\sim 500 \mathrm{hPa}$ (not shown). Note that the low values of $w$ are due to the averaging over 30 years (1971-1999). At all levels, the spatial distribution of $w$ is very similar between CLM7 and CLM7_conv, while CLM2.8 shows a larger spatial variability of $w$ compared to coarser resolution thanks to a more detailed representation of the orographic features. In CLM2.8, the areas of convergence and divergence are more consistent with the orography leading to a more realistic representation of orographic circulation systems, which are highly relevant for the initiation of convection in the area (Kalthoff et al. 2009). Additionally, the diurnal cycle of the instantaneous maximum $w$ (Fig. 9) reveals more intense updrafts in the CLM2.8 simulation compared to CLM7 and CLM7_conv (not shown), especially at $\sim 850 \mathrm{hPa}$. Note that the diurnal cycle of $w$ for CLM2.8 peaks at 15:00 in agreement with the maximum in mid-level cloud coverage at this time, and the convective precipitation maximum between 15:00 and 18:00.

\section{Summary and conclusions}

In the present study, we assess the effects of increasing spatial resolution on simulated precipitation and the atmospheric conditions leading to convective precipitation. Especially, we investigate the improvements at spatial scales 
where it is possible to switch off most convective parameterisations, so-called convection permitting scales. Added values of convection permitting model simulations have been shown by several studies in the NWP field (Mass et al. 2002; Miura et al. 2007; Richard et al. 2007; Lean et al. 2008; Weusthoff et al. 2010; Baldauf et al. 2011). Our study aims to bridge the gap between these findings in NWP mode and climate time scales. In this context, 30 years were simulated at both a $7 \mathrm{~km}$ (CLM7) and a $2.8 \mathrm{~km}$ (CLM2.8) resolution with COSMO-CLM. The simulations are evaluated over the state of Baden-Württemberg in southwestern Germany, which is a region known for the orographically induced convective precipitation. A precipitation gauge network of high temporal resolution and dense spatial density is used for the evaluation, along with the gridded daily resolution REGNIE data set.

The CLM2.8 and CLM7 simulations show similar results for mean seasonal precipitation, although with some decrease in the wet bias for CLM2.8, especially in summer, and some differences in the spatial patterns, especially in connection with steep orography. Furthermore, CLM2.8 reduces the drizzle problem, which affects CLM7 (Berg et al. 2013). In fact, CLM2.8 better represents the number of dry days in winter as well as in summer, but it is still underestimating this statistic. CLM2.8 performs very well regarding the distribution of hourly precipitation intensities in summer, while in winter it underestimates higher intensities, although an improvement respect to CLM7 is visible. However, at the daily temporal resolution, CLM2.8 severely overestimates the probability of higher intensities, especially in summer. A more detailed analysis of the problem in this season reveals that the mismatch between the results on different temporal scale is due to events lasting too long in the simulation. Our conclusion is that CLM2.8 creates events similarly to observations but it extends them with low intensity precipitation, behaviour leading to an increase of the daily intensities. It is also clear that a monthly or even daily scale normally used to evaluate CLM7 is not sufficient to appreciate the added values of CLM2.8.

The diurnal precipitation cycle of CLM2.8 is strikingly similar to observations concerning the position of the primary afternoon peak in summer. CLM7 shows severe problems for the diurnal cycle, with a strong peak at midday; several hours too early when compared to observations. We show that this behaviour is a direct consequence of the convective parameterisation used, but we also show that parameterisation is still needed at this resolution. The analysis of the diurnal cycle of temperature and specific humidity shows in general similar behaviour between CLM7 and CLM2.8. However, CLM2.8 presents higher humidity in the afternoon, which could be responsible of the more unstable atmosphere in this simulation. An investigation of the CAPE index reveals that the expected link between atmospheric instability and consequent convective precipitation occurrence is maintained only when convection is resolved. The Tiedtke (1989) parameterisation used for CLM7 is shown to largely ignore the physical connection to CAPE. This is in agreement with previous findings of Baldauf et al. (2011), who found that the parameterisation, to some extent, decouples the initiation of convection from the boundary layer conditions leading to it. On the other hand, CLM7 resolution is too coarse to properly solve convective processes. The expected relationship between CAPE and precipitation maximum is found in the additional short simulation performed at $7 \mathrm{~km}$ resolution, but with the main convective parameterisation switched off (CLM7_conv). Nevertheless, CLM7_conv clearly fails in representing the diurnal cycle of precipitation. It is clear that the Tiedtke scheme used for convection in CLM is not applicable for the $7 \mathrm{~km}$ resolution. Other schemes, such as the Kain-Fritsch scheme (Kain 2004) that better represents higher spatial resolutions (Jones et al. 2004), might be more appropriate.

Through the study of the vertical profiles of humidity and temperature, we found that the different boundary layer conditions in the CLM7 and CLM2.8 simulations lead to a lower LCL and LFC in CLM7 in comparison with CLM2.8. This could result in clouds forming more easily at low levels and thus generating drizzle; a known problem affecting $7 \mathrm{~km}$ resolution. At the contrary, higher LCL and LFC in CLM2.8 contribute to the moisture and temperature accumulation especially in the afternoon, causing deep convection and probably higher intensity precipitation. These conditions are likely linked to a reduced low-level cloud cover at 12:00 for CLM2.8, which could be responsible for the increase of both direct and diffusive shortwave radiation. CLM2.8 partially corrects the underestimation (overestimation) of shortwave (longwave) net radiation that according to Jaeger et al. (2008) affects coarser resolution simulations with CLM. CLM2.8 allows a representation of the spatial distribution of vertical velocity more consistent with the orographic features of the area. A more accurate representation of the areas of convergence is a crucial element for the initiation of convection over complex terrains (Barthlott et al. 2006), such as the area under investigation. Moreover, higher spatial resolution leads to substantially higher values of $w$ in comparison with CLM7 up to the daily maximum at 15:00 in agreement with mid-level cloud coverage and convective precipitation maximum.

A problem with CLM2.8 is that the precipitation events seem to cluster into too long events compared to observations, likely due to extending the events with low intensity precipitation. This problem needs to be further analysed in shorter simulations. The large bias in mean precipitation, especially pronounced in winter is present in all three nests 
of the downscaling simulations. It is thus difficult to state whether the model is producing the overestimations independently at each resolution, or whether the atmospheric state (for e.g. temperature gradient, water vapour content) leading to the precipitation bias is simply carried further to the higher resolutions. The small differences between the simulations in winter are probably due to the dominance of the large-scale circulation, which is not as dependent on higher resolution, and the inactivity of the convective scheme for this season. On the other hand, also the relative small size of the CLM2.8 domain could generate a too strong dependency on the driving coarser resolution in this season.

Our results show clear improvements at convection permitting scale for higher temporal resolution of precipitation. This has great value for many impact assessment models where both high spatial and temporal resolution are necessary, e.g. in soil erosion modelling or urban drainage planning. Taking the step away from convection parameterisation could significantly improve sub-daily statistics of RCMs, and getting the diurnal cycle right for the right reasons could allow for a better insight in expected changes in precipitation extremes of short duration (Lenderink and van Meijgaard 2008).

Acknowledgments The authors acknowledge funding, within the KLIWA-project "Bodenabtrag durch Wassererosion in Folge von Klimaveränderungen", from Bavarian State Ministry of the Environment and Public Health, Ministry of Economics, Climate Protection, Energy and Regional Planning of the German State Rheinland-Pfalz and Ministry of the Environment, Climate Protection and the Energy Sector Baden-Württemberg. The CLM simulations were carried out at HLRS at the University of Stuttgart within the project "High resolution regional climate modelling" (HRCM). The authors are grateful to the German Weather Service (DWD) and to the State Institute for Environmental Protection Baden-Württemberg (LUBW) for data supply and cooperation. We would also extend a great thank you to the CLM-modelling community, particularly H.-J. Panitz from KIT-IMK for assistance with the RCM simulations. Finally, we would like to acknowledge the work of the R Development Core Team (2011), and the developers of CDO.

Open Access This article is distributed under the terms of the Creative Commons Attribution License which permits any use, distribution, and reproduction in any medium, provided the original author(s) and the source are credited.

\section{References}

Baldauf M, Seifert A, Förstner J, Majewski D, Raschendorfer M, Reinhardt $\mathrm{T}$ (2011) Operational convective-scale numerical weather prediction with the COSMO model: description and sensitivities. Mon Weather Rev. doi: 10.1175/MWR-D-10-05013.1

Bartels H, Dietzer B, Malitz G, Albrecht FM, Guttenberger J (2006) KOSTRA-DWD-2000 Starkniederschlagshöhen für Deutschland (1951-2000). Deutscher Wetterdienst, Offenbach

Barthlott C, Corsmeier U, Meißner C, Braun F, Kottmeier C (2006) The influence of mesoscale circulation systems on triggering convective cells over complex terrain. Atmos Res 81:150-175
Barthlott C, Schipper JW, Kalthoff N, Adler B, Kottmeier C, Blyth A, Mobbs S (2010) Model representation of boundary-layer convergence triggering deep convection over complex terrain: a case study from COPS. Atmos Res 95(2-3):172-185. doi:10.1016/j.atmosres.2009.09.010

Bechtold P, Chaboureau JP, Beljaars A, Betts AK, Köhler M, Miller M, Redelsperger JL (2004) The simulation of the diurnal cycle of convective precipitation over land in a global model. Q J R Meteorol Soc 130:3119-3137

Berg P, Wagner S, Kunstmann H, Schädler G (2012) High resolution regional climate model simulations for Germany: part I-validation. Clim Dyn 40:401-414. doi:10.1007/s00382-012-1508-8

Berg P, Moseley C, Haerter JO (2013) Strong increase in convective precipitation in response to higher temperatures. Nat Gesci 6:181-185. doi:10.1038/ngeo1731

Boberg F, Berg P, Thejll P, Gutowski W, Christensen JH (2009) Improved confidence in climate change projections of precipitation evaluated using daily statistics from the PRUDENCE ensemble. Clim Dyn 32(7-8):1097-1106. doi:10.1007/s00382-008-0446-y

Boberg F, Berg P, Thejll P, Gutowski W, Christensen JH (2010) Improved confidence in climate change projections of precipitation further evaluated using daily statistics from ENSEMBLES models. Clim Dyn 35(7-8):1509-1520. doi:10.1007/ s00382-009-0683-8

Böhm U, Kücken M, Ahrens W, Block A, Hauffe D, Keuler K, Rockel B, Will A (2006) CLM-the climate version of LM: brief description and long-term applications. COSMO Newsletter No 6, Deutscher Wetterdienst, Offenbach

Brockhaus P, Lüthi D, Schär C (2008) Aspects of the diurnal cycle in a regional climate model. Meteorol Z 17:433-443

Brommundt J, Bárdossy A (2007) Spatial correlation of radar and gauge precipitation data in high temporal resolution. Adv Geosci 10:103-109

Brooks HE, Doswell CA III, Wicker LJ (1993) STORMTIPE: a forecasting experiment using a three-dimensional cloud model. Weather Forecast 8:352-362

Cleveland WS, Devlin SJ (1988) Locally weighted regression: an approach to regression analysis by local fifing. J Am Stat Assoc 83:596-610

Colby FP (1984) Convective inhibition as a predictor of convection during AVE-SESAME-2. Mon Weather Rev 112:2239-2252

Crook NA (1996) Sensitivity of moist convection forced by boundary layer processes to low-level thermodynamic fields. Mon Weather Rev 124:1768-1785

Dai A (2006) Precipitation characteristics in eighteen coupled climate models. J Clim 19:4605-4630

Dai A, Trenberth KE (2004) The diurnal cycle and its depiction in the community climate system model. J Clim 5:930-951

Dietzer B (2003) Berechnung von Gebietsniederschlags höhen nach dem Verfahren REGNIE. Deutscher Wetterdienst, Offenbach

Doms G, Förstner J, Heise E, Herzog HJ, Mironov D, Raschendorfer M, Reinhardt T, Ritter B, Schrodin R, Schulz JP, Vogel G (2011) A description of the nonhydrostatic regional COSMO model, part II: physical parameterization. Deutscher Wetterdienst, Offenbach

Efron B, Tibshirani RJ (1993) An introduction to the bootstrap. Chapman \& Hall, New York

Emanuel KA (1994) Atmospheric convection. Oxford University Press, Oxford

Fiedler F, Bischoff-Gauß I, Kalthoff N, Adrian G (2000) Modeling of transport and dispersion of SF6 in the Freiburg-Schauinsland area. J Geophys Res 105(D1):1599-1610

Grell GA, Schade L, Knoche R, Pfeiffer A, Egger J (2000) Nonhydrostatic climate simulations of precipitation over complex terrain. $\mathrm{J}$ Geophys Res 105:29595-29608

Haerter JO, Berg P (2009) Unexpected rise in extreme precipitation caused by a shift in rain type? Nat Geosci 2:372-373 
Haerter JO, Berg P, Hagemann S (2010) Heavy rain intensity distributions on varying time scales and at different temperatures. J Geophys Res 115(D17102). doi:10.1029/2009JD013384

Hohenegger C, Brockhaus P, Schär C (2008) Towards climate simulations at convection permitting scales. Meteorol Z 17:383-394

Jaeger EB, Anders I, Lüthi D, Rockel B, Schär C, Seneviratne SI (2008) Analysis of ERA40-driven CLM simulations for Europe. Meteorol Z 17:349-367

Jones C, Willén U, Ullerstig A, Hansson U (2004) The Rossby Centre regional atmospheric climate model part I: model climatology and performance for the present climate over Europe. AMBIO 33(4):199-210. doi:10.1579/0044-7447-33.4.199

Kain JS (2004) The Kain-Fritsch convective parameterization: an update. J Appl Meteorol 43:170-181

Kalthoff N, Horlacher V, Corsmeier U, Volz-Thomas A, Kolahgar B, Geiß H, Möllmann-Coers M, Knaps A (2000) The influence of valley winds on transport and dispersion of airborne pollutants in the Freiburg-Schauinsland area. J Geophys Res 105(D1):1585-1597

Kalthoff N, Adler B, Barthlott C, Corsmeier U, Mobbs S, Crewell S, Trumner K, Kottmeier C, Wieser A, Smith V (2009) The impact of convergence zones on the initiation of deep convection: a case study from COPS. Atmos Res 93:680-694

Kessler E (1969) On the distribution and continuity of water substance in the atmospheric circulations, vol 32 of meteorological monographs vol. 10, American Meteorological Society, Boston

Khodayar S, Kalthoff N, Wickert J, Corsmeier U, Morcrette CJ, Kottmeier C (2010) The increase of spatial data resolution for the detection of the initiation of convection. A case study from CSIP. Meteorol Z 19:179-198

Khodayar S, Kalthoff N, Schaedler G (2013) Impact of soil moisture variability in seasonal climatic simulations of convective precipitation over a complex terrain. Part I: validation, local feedbacks and realistic initialization. Meteorol $\mathrm{Z}$. doi:10.1127/0941-2948/2013/0403

Koßmann M, Fiedler F (2000) Diurnal momentum budget analysis of thermally induced slope winds. Meteorol Atmos Phys 75:195-215

Kottmeier C, Kalthoff N, Barthlott C et al (2008) Mechanisms initiating deep convection over complex terrain during COPS. Meteorol Z 17:931-948. doi:10.1127/0941-2948/2008/0348

Langhans W, Schmidli J, Fuhrer O, Bieri S, Schär C (2013) Longterm simulations of thermally-driven flows and orographic convection at convection-parameterizing and convection permitting resolutions. J Appl Meteorol Clim 52:1490-1510. doi:10.1175/JAMC-D-12-0167.1

Lean HW, Clark PA, Dixon M, Roberts NM, Fitch A, Forbes R, Halliwell C (2008) Characteristics of high-resolution versions of the Met Office Unified Model for forecasting convection over the United Kingdom. Mon Weather Rev 136:3408-3424

Lenderink G, van Meijgaard E (2008) Increase in hourly precipitation extremes beyond expectations from temperature changes. Nat Geosci 1:511-514
Mass CF, Ovens D, Westrick K, Colle BA (2002) Does increasing horizontal resolution produce more skillful forecasts? Bull Am Meteorol Soc 83:407-430

Meißner C, Kalthoff N, Kunz M, Adrian G (2007) Initiation of shallow convection in the Black Forest Mountains. Atmos Res $86: 42-60$

Miura H, Satoh M, Tomita H, Noda AT, Nasuno T, Iga S (2007) A short-duration global convection permitting simulation with a realistic land and sea distribution. Geophys Res Lett 34(L02804). doi:10.1029/2006GL027448

Moncrieff MW, Miller MJ (1976) The dynamics and simulation of tropical cumulonimbus and squall lines. Q J R Meteorol Soc 102:373-394

Prein A, Gobiet A, Suklitsch M et al (2013) Added value of convection permitting seasonal simulations. Clim Dyn. doi:10.1007/ s00382-013-1744-6

Raschendorfer M (2001) The new turbulence parameterization of LM. COSMO newsletter 1, Deutscher Wetterdienst, Offenbach

Richard E, Buzzi A, Zängl G (2007) Quantitative precipitation forecasting in the Alps: the advances achieved by the Mesoscale Alpine Programme. Q J R Meteorol Soc 133:831-846

Ritter B, Geleyn JF (1992) A comprehensive radiation scheme for numerical weather prediction models with potential applications in climate simulations. Mon Weather Rev 120:303-325

Schwartz CS, Kain JS, Weiss SJ, Xue M, Bright DR, Kong F, Thomas KW, Levit JJ, Coniglio MC (2009) Next-day convectionallowing WRF model guidance: a second look at $2 \mathrm{~km}$ versus $4 \mathrm{~km}$ grid spacing. Mon Weather Rev 137:3351-3372

Steppeler J, Doms G, Schättler U, Bitzer HW, Gassmann A, Damrath U, Gregoric G (2003) Meso-Gamma scale forecasts using the nonhydrostatic model LM. Meteorol Atmos Phys 82:75-96. doi:10.1007/s00703-001-0592-9

Tiedtke M (1989) A comprehensive mass flux scheme for cumulus parameterization in large-scale models. Mon Weather Rev 117:1779-1800

Uppala SM, Kållberg PW, Simmons AJ et al (2005) The ERA40 re-analysis. Q J R Meteorol Soc 131:2961-3012. doi:10.1256/qj.04.176

Weckwerth T (2000) The effect of small-scale moisture variability on thunderstorm initiation. Mon Weather Rev 128:4017-4030. doi:10.1175/1520-0493(2000)129<4017:TEOSSM>2.0.CO;2

Weisman ML, Skamarock WC, Klemp JB (1997) The resolution dependence of explicitly modeled convective systems. Mon Weather Rev 125(4):527-548

Weusthoff T, Ament F, Arpagaus M, Rotach MW (2010) Assessing the benefits of convection-permitting models by neighborhood verification: examples from MAP D-PHASE. Mon Weather Rev 138:3418-3433

Yang GY, Slingo J (2001) The diurnal cycle in the tropics. Mon Weather Rev 129:784-801 